\title{
N-Substituted pyridazines as building blocks in novel supramolecular architectures ${ }^{\dagger}$
}

\author{
Sunil Varughese, Gareth Cooke and Sylvia M. Draper*
}

Received 10th February 2009, Accepted 11th May 2009

First published as an Advance Article on the web 1st June 2009

DOI: $10.1039 / b 902765 c$

\begin{abstract}
A series of mono, 1,4-di and 1,3,5-tri 4-substituted 3,6-di(2pyridyl)pyridazines were analyzed to evaluate the substituent and steric effects in the crystal packing.
\end{abstract}

Renewed interest in pyridazine chemistry arises from the potential that they have shown in the formation of polynuclear coordination assemblies with diverse topologies including [2 $[2]$ grids, ${ }^{1}$ metallocryptand cages ${ }^{2}$ and helices. ${ }^{3}$ One of the best studied compounds in this class is 3,6-di(2-pyridyl)pyridazine and its derivatives. ${ }^{4 b}$ The

School of Chemistry, Trinity College, Dublin, D2, Ireland. E-mail: smdraper@tcd.ie; Tel: +353(0)18962026

$\dagger$ Electronic supplementary information (ESI) available: Crystallographic details, additional Figures, TGA plots and normalized absorbance spectra of $\mathbf{1}, \mathbf{2}$ and $\mathbf{3}$, hydrogen bond table, torsion angles, synthesis and spectral analysis. CCDC reference numbers 690255, 693497 and 719943. For ESI and crystallographic data in CIF or other electronic format see DOI: 10.1039/b902765c
$\mathrm{N}$-atoms present multiple coordination sites and their attachments to a variety of metal centres including $\mathrm{Cu}(\mathrm{I}), \mathrm{Ni}(\mathrm{II})$ and $\mathrm{Ag}(\mathrm{I})$ facilitate spectroscopic investigation of the resulting photophysical, magnetic and electrochemical properties of any emerging complex array. ${ }^{5}$ Sterically demanding substituents on the pyridazine ring can force the neighbouring aromatic rings to twist away from the pyridazine ring plane, thus influencing the entire topological and coordination environment. ${ }^{6}$ Consequently, selective substitution onto the pyridazine ring offers a mechanism for the manipulation and control of the three-dimensional nature of the assembly.

Building on our growing interest in N-rich polyaromatic hydrocarbons, we have generated three aromatically 4-substituted 3,6-di(2pyridyl)pyridazines 1, 2 and 3 (Scheme 1) \& These compounds were synthesized by the inverse electron demand Diels-Alder reaction between 3,6-di(2-pyridyl)-1,2,4,5-tetrazine and the corresponding alkynes. ${ }^{10}$ There is a correlation between the number of ethynyl units and the temperature employed for the reaction as represented in Scheme 2 (better yields were obtained for the less reactive di- and
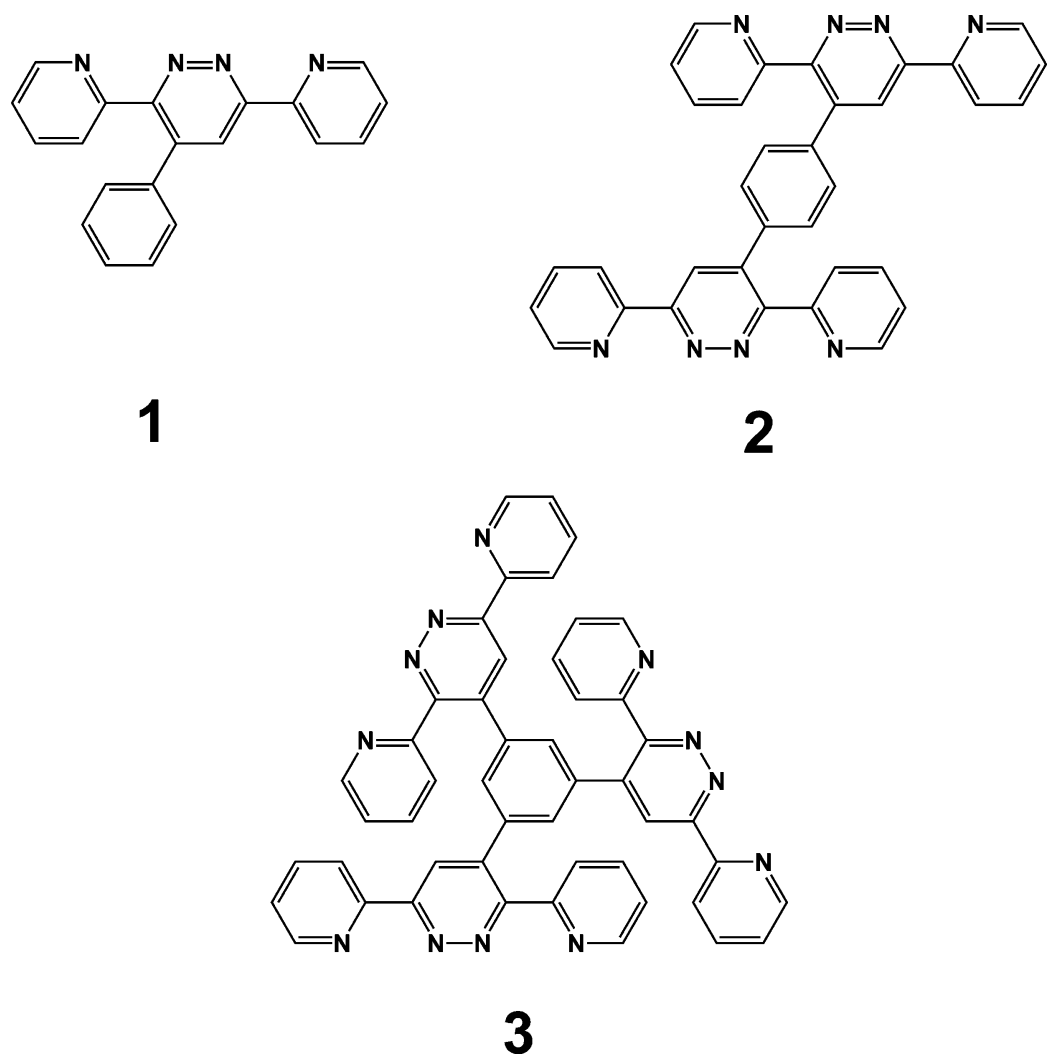

Scheme 1 The chemical structures of the molecules. 


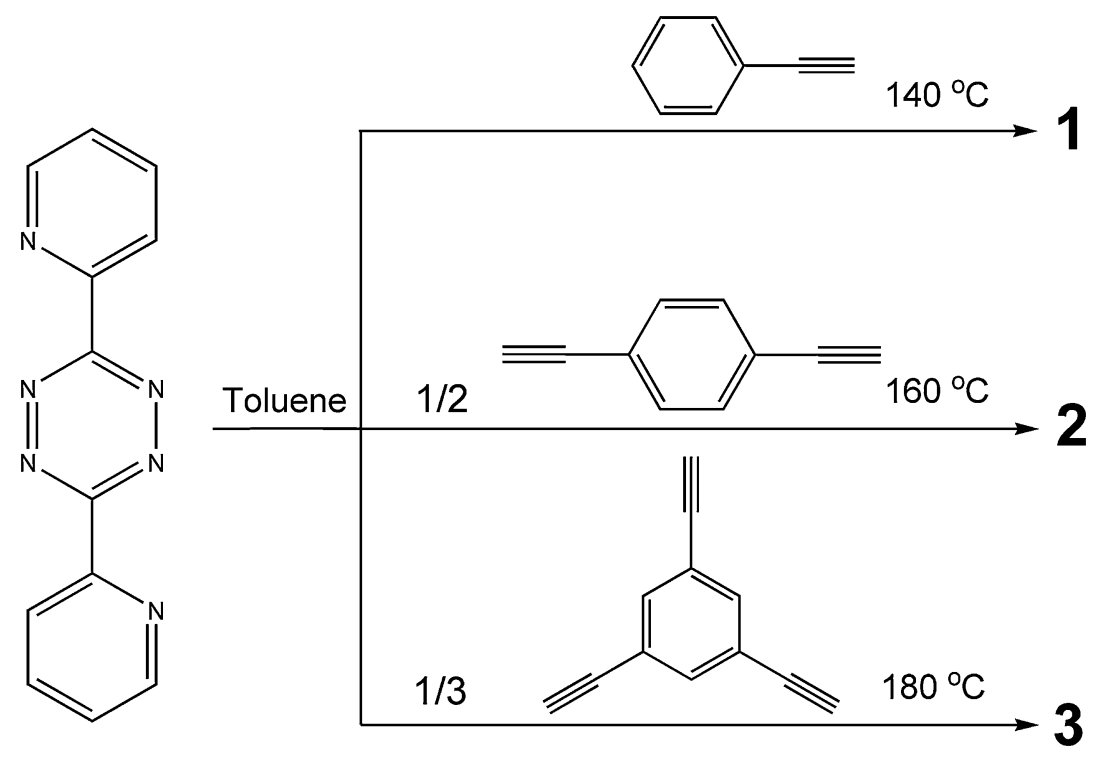

Scheme 2 Schematic representation of typical reaction conditions utilized in the synthesis of $\mathbf{1}, \mathbf{2}$ and $\mathbf{3}$.

tri- ethynyl benzenes on raising the reaction temperature). The products were characterized using $1 \mathrm{D}{ }^{1} \mathrm{H}$ and ${ }^{13} \mathrm{C}, 2 \mathrm{D}{ }^{1} \mathrm{H}-{ }^{1} \mathrm{H}$ COSY and ${ }^{13} \mathrm{C}-{ }^{1} \mathrm{H}$ COSY NMR techniques, thermogravimetry, absorption spectroscopy and single crystal X-ray diffraction. $\dagger$

The compounds $\mathbf{1}$ and $\mathbf{2}$ have been prepared using a differing synthetic strategy elsewhere but a more efficient method for the preparation of these compounds has been adopted here and has been reported for $3{ }^{4}$ Together they form an interesting series, each with a common central benzene unit which is either mono-, 1,4-di- or 1,3,5-tri-substituted. The result is a set of related aromaticised pyridazines with differing symmetry. Also, it was anticipated that the additional pyridyl substituents on the pyridazine would contribute significantly to the observation of intermolecular interactions in the solid state. Thus, we have conducted a systematic study of these interesting functional molecules and the supramolecular assemblies that they form.

The monosubstituted pyridazine derivative, 4-phenyl-3,6-di(2pyridyl) pyridazine, 1 , crystallizes in a monoclinic, $P 2_{1} / n$ space group: with one molecule in the asymmetric unit. Of the four rings present, the pyridazine ring and one of the 2-pyridyl moieties are found to be in a plane, while the other two rings, deviate from the mean plane by $30.92^{\circ}$ (2-pyridyl) and $58.94^{\circ}$ (phenyl) respectively. Thus, the 4substitution has brought about considerable variation in the torsion angles of the 2-pyridyl moieties from that observed in the case of the parent pyridazine ligand, 3,6-di(2-pyridyl)pyridazine (14.05 ${ }^{\circ}$ and $6.88^{\circ}$ respectively). ${ }^{7}$ Further, the torsion angle exhibited by the phenyl ring is comparable to that of similar ligands reported. ${ }^{4 c}$ In the crystal lattice, the molecules undergo self-assembly to form a centrosymmetric close packed structure, as shown in Fig. 1. The molecules in the crystal lattice are stabilized by several $\mathrm{C}-\mathrm{H}_{\text {(pyridine) }} \cdots \pi_{\text {(pyridine) }}(\sim 2.89$ $\AA$ A) and edge to centroid type $\pi_{\text {(pyridine) }} \cdots \pi_{\text {(pyridazine) }}$ interactions (with an average distance of $3.34 \AA$ ).$\S$ The intermolecular $\mathrm{C}-\mathrm{H} \cdots \mathrm{N}$ hydrogen bonds are formed exclusively between the benzene and pyridazine rings. These are predominantly $\mathrm{C}-\mathrm{H}_{\text {(benzene) }} \cdots \mathrm{N}_{\text {(pyridazine) }}$ $\left(\mathrm{C} \cdots \mathrm{N}, 3.66 \AA, 149^{\circ}\right)$ and edge-type $\mathrm{C}-\mathrm{H}_{\text {(pyridazine) }} \cdots \pi_{\text {(benzene) }}(3.22$ A) interactions. Surprisingly, none of the 2-pyridyl moieties play a role in the formation of $\mathrm{C}-\mathrm{H} \cdots \mathrm{N}$ hydrogen bonds, while the phenyl (a)
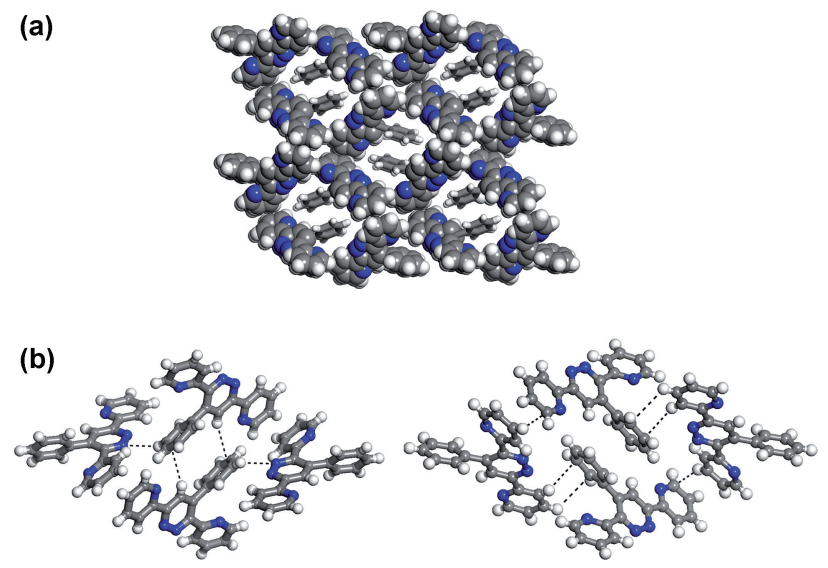

Fig. 1 (a) The three-dimensional packing of 1. (b) The pictorial representation of various intermolecular interactions observed in the assembly.

$\mathrm{H}$-atom, which is considered to be less prone to form hydrogen bonds, interacts with the pyridazine ring to form $\mathrm{C}-\mathrm{H} \cdots \mathrm{N}$ interactions.

In the case of 1,4-benzene-bis(3,6-di(2-pyridyl)pyridazine), 2 , a three-fold symmetry is observed in the crystal lattice (trigonal, $R \overline{3}$ ) although the molecule lacks any $C_{3}$ symmetry. The molecule of $\mathbf{2}$ is sitting on an inversion centre and only half of the molecule is present in the asymmetric unit. Triangular units, with a side length of 21.92 $\AA$, are formed by the interlocking of three H-shaped molecules (Fig. 2). The adjacent molecules within a triangular assembly are stabilized by several $\pi \cdots \pi$ interactions in the range $3.37-3.56 \AA$ and C-H $\cdots \pi$ interactions $(2.78 \AA$ A) $\S$ The 2-pyridyl and pyridazine functionalities also play a role in stabilizing the triangular unit. In each triangular unit, a two tier hydrogen bond network is formed. While the inner core is stabilized by the hydrogen bonds involving three internally oriented 2-pyridyl units $\left(\mathrm{C}-\mathrm{H}_{\text {(pyridine) }} \cdots \mathrm{N}_{\text {(pyridine) }}, \mathrm{C} \cdots \mathrm{N}\right.$ $3.78 \AA, 158^{\circ}$ ), the peripheral area is bound by bifurcated hydrogen bonds formed by the pyridazine moiety $\left[\mathrm{C}-\mathrm{H}_{\text {(pyridine) }} \cdots \mathrm{N}_{\text {(pyridazine) }}\right.$ C $\cdots$ N 3.32 and $3.28 \AA$ A, (angles $142^{\circ}$ and $134^{\circ}$ respectively)]. These interactions are extended in one dimension to form a helical assembly, as schematically represented in the bottom panel of Fig. 2. 

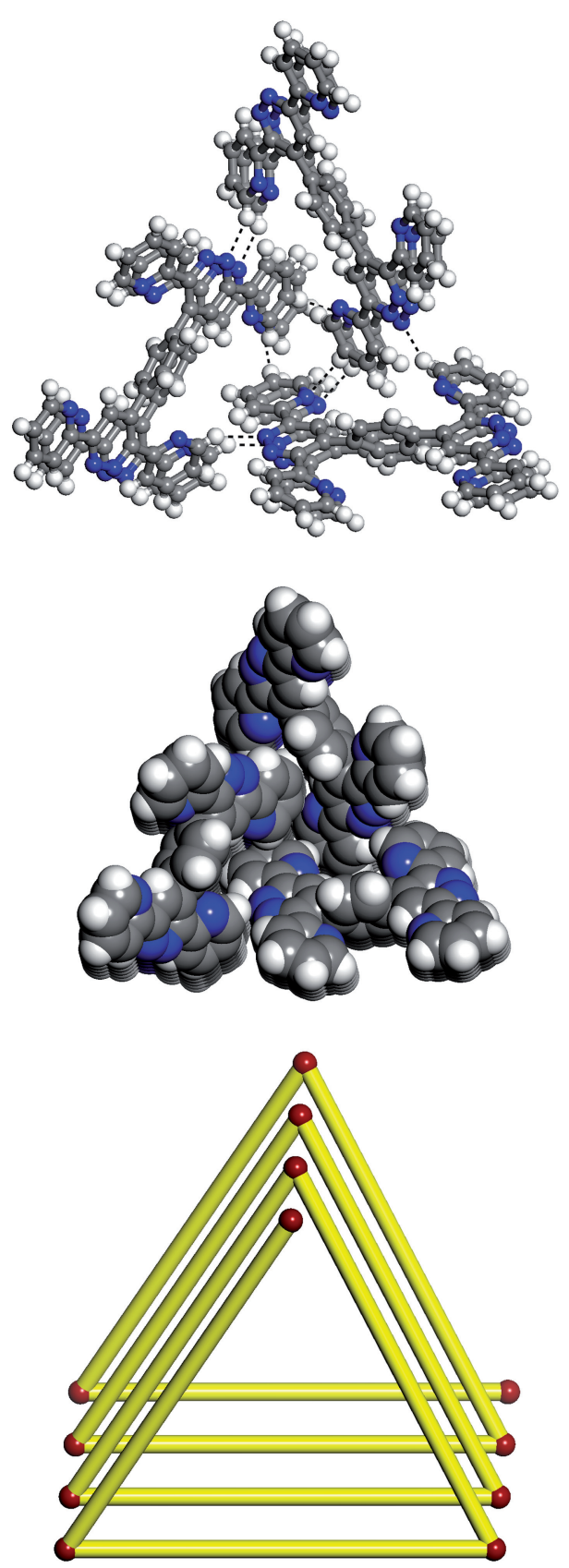

Fig. 2 The pictorial representation of intermolecular interactions observed in the triangular supramolecular entity (top). The space fill model of the triangular unit (middle). The schematic representation of the helix, using the node and connector strategy (bottom).

In the three-dimensional arrangement, the triangular helical entities undergo self-assembly to form a hexagonal network with onedimensional channels $(12.45 \times 12.45 \AA)$. The channels are occupied by disordered solvent (water) molecules. ${ }^{8}$ The guest water molecules are lost at $137{ }^{\circ} \mathrm{C}(\sim 2 \%)$ and the assembly collapses at $300{ }^{\circ} \mathrm{C}$, as revealed by thermogravimetric analysis.

Two solid-state forms of $\mathbf{2}$, an anhydrous and a $\mathrm{CHCl}_{3}$ solvated form, were identified and structurally characterized. ${ }^{4 b}$ However, unlike the porous assembly observed in the present study (Fig. 3), these systems comprise parallel columns of molecules in which, the assemblies were stabilized by extensive $\pi \cdots \pi$ interactions. Clearly,

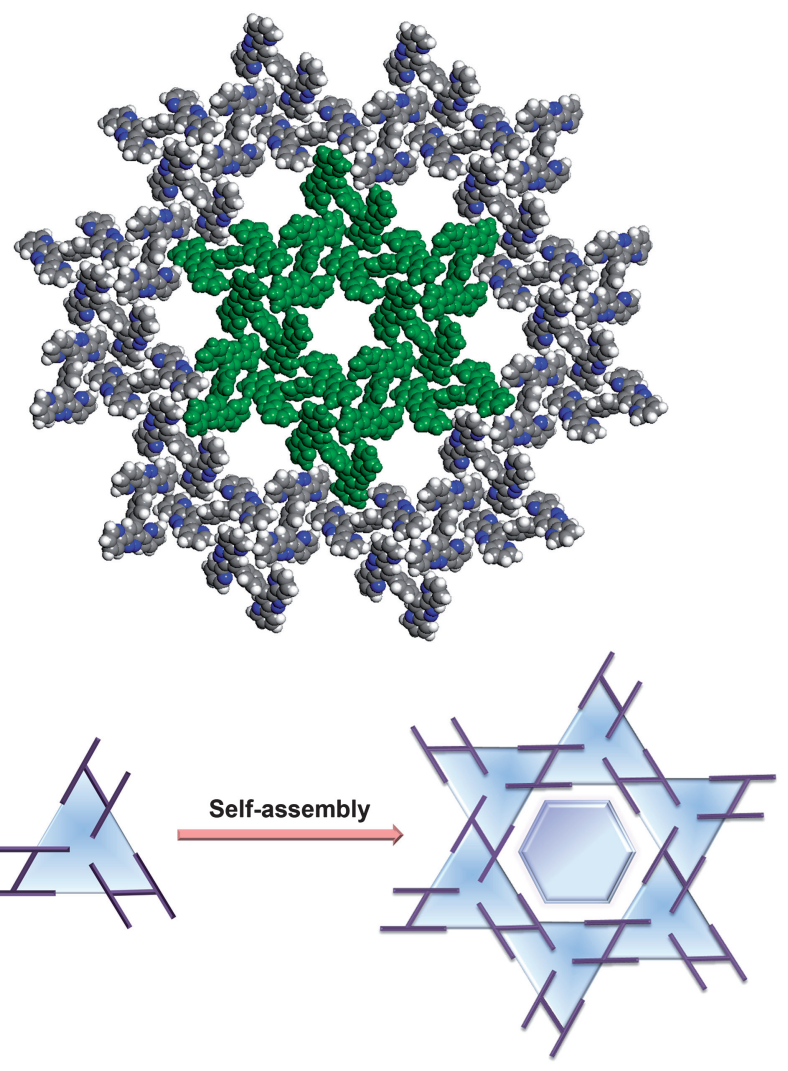

Fig. 3 The porous assembly formed by the self-assembly of $\mathbf{2}$ and the schematic representation of the self-assembly of the triangular units to form a porous hexagonal framework.

the conformational flexibility of $\mathbf{2}$ and the presence of several hydrogen bond forming functionalities make it a good candidate for the preparation of polymorphic forms.

Pale yellow crystals of $\mathbf{3}$ were grown by the solvent diffusion of ether into a $\mathrm{CH}_{2} \mathrm{Cl}_{2}$-methanol solution. Crystal structure analysis revealed that 3 crystallizes in a triclinic crystal system $\neq$ and forms a host-guest complex with the solvent of crystallization, diethyl ether, occupying the void space. Although a three-fold symmetry was expected, the molecule exhibits a paddle-wheel topology, possibly due to the steric hindrance about each pyridazine.

The host assembly formed is stabilized by two types of recognition pattern involving the 2-pyridyl moiety and the pyridazine units, as shown in Fig. 4. While the pyridazine ring is involved in the formation of bifurcated $\mathrm{C}-\mathrm{H} \cdots \mathrm{N}(\mathrm{H} \cdots \mathrm{N}, 2.62$ and $2.71 \AA)$ interactions, the pyridyl moiety forms centrosymmetric $\mathrm{C}-\mathrm{H} \cdots \mathrm{N}\left(\mathrm{C} \cdots \mathrm{N} 3.53 \AA .142^{\circ}\right)$ hydrogen bonds. The guest molecule in the void space is stabilized by $\mathrm{C}-\mathrm{H}_{\text {(ether) }} \cdots \pi$ interactions, involving an ethyl group and the aromatic rings. $\S$ Thermal analysis revealed weight loss of $\sim 18.5 \%$ under 400 ${ }^{\circ} \mathrm{C}$ and the decomposition of the framework thereafter. This weight reduction occurs in stages and may be due to the loss of the guest diethyl ether $(8.7 \%)$ until $160{ }^{\circ} \mathrm{C}$ followed by the loss of an equivalent of one pyridine moiety per molecule $(9.8 \%)$.

The absorption spectral analysis revealed that, as expected, all three molecules exhibit similar electronic excitation. While in the cases of $\mathbf{1}$ and $\mathbf{3}, \lambda_{\max }$ was identical (282 nm), 2 exhibited a slight red shift with $\lambda_{\max }=288 \mathrm{~nm}$.

Thus, varying the degree of substitution and the recognition pattern has resulted in changes in the three-dimensional architecture 

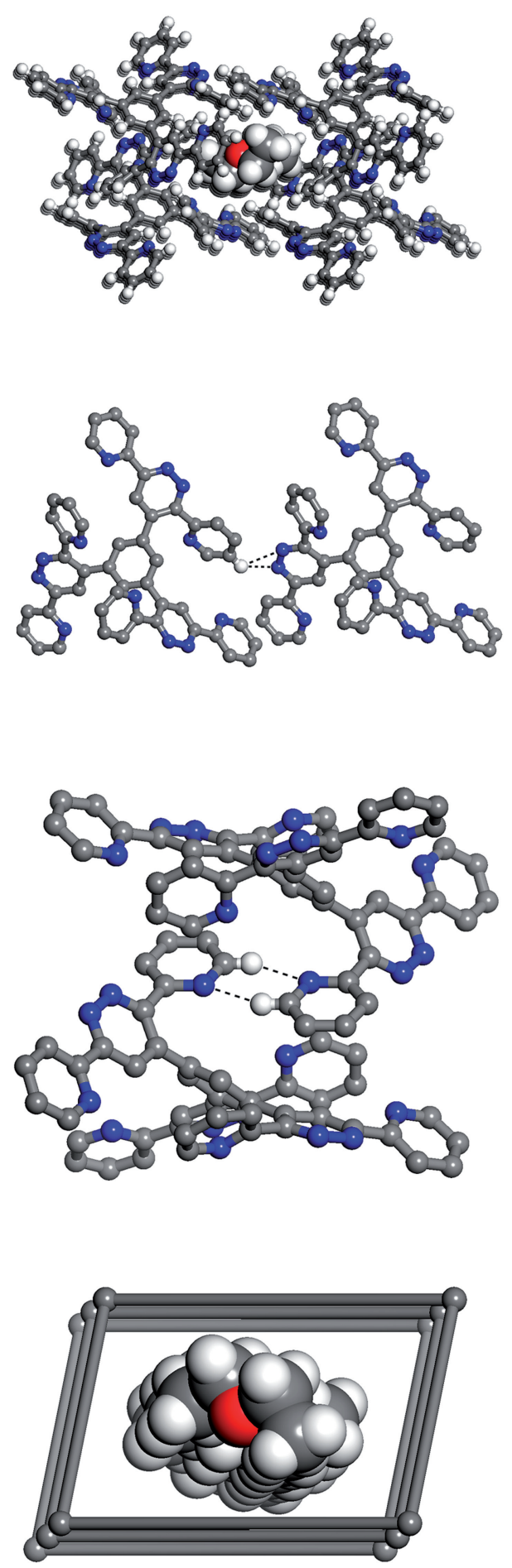

Fig. 4 Top image: the host-guest complex formed by the self-assembly of 3 , with the diethyl ether molecule occupying the cavity represented in space filling mode. The middle two images illustrate the type of recognition pattern involved in the stabilization of the host-framework. The bottom image is a schematic representation of the square network.

of the resulting assemblies. While the asymmetric molecule $\mathbf{1}$ yielded a centrosymmetric close-packed structure, the interlocking of the $\mathrm{H}$ type molecules of $\mathbf{2}$ led to the formation of a porous assembly. The asymmetric compound $\mathbf{3}$ yielded a host-guest lattice, thus providing further evidence of the preparation of porous assemblies by the utilization of molecules with uneven topology. ${ }^{9}$ This points towards the difficulty of predicting crystal topology merely from the consideration of the symmetry of molecular building units. The variation in the resultant topologies is clearly dependent on a fine balance of intermolecular interactions, enthalpy, entropy and steric considerations in the crystal lattice.

In all three complexes, the resulting assemblies are stabilized by $\mathrm{C}-$ $\mathrm{H} \cdots \pi, \pi \cdots \pi$ and numerous weak $\mathrm{C}-\mathrm{H} \cdots \mathrm{N}$ interactions. The present study adds to the existing knowledge of the cumulative effect and the utility of multiple weak interactions in the preparation and stabilization of supramolecular assemblies. The preparation of coordination complexes of these ligands and their isomers is in progress. The structural characterization of the resulting assemblies and their photophysical properties will be reported in due course.

\section{Notes and references}

\$ Crystal data for 1 (CCDC 693497): $\dagger\left(\mathrm{C}_{20} \mathrm{H}_{14} \mathrm{~N}_{4}\right)$, monoclinic, $P 2_{1} / n$, $a=6.164(6), b=14.713(1), c=17.365(1) \mathrm{A}, \beta=95.38(1)^{\circ}, V=$ $1567.9(15) \AA^{3}, Z=4, T=123(2) \mathrm{K}, R_{1}=0.0404$, w $R_{2}=0.1043$.

Crystal data for 2 (CCDC 690256): $\dagger\left(\mathrm{C}_{34} \mathrm{H}_{22} \mathrm{~N}_{8}\right)$, trigonal, $R \overline{3}, a=$ $36.000(1), b=36.000(1), c=6.213(5) \AA, V=6973(6) \AA^{3}, Z=9, T=$ $123(2) \mathrm{K}, R_{1}=0.0408, \mathrm{w} R_{2}=0.1077$.

Crystal data for 3 (CCDC 690255): $\dagger\left(\mathrm{C}_{48} \mathrm{H}_{30} \mathrm{~N}_{12} \cdot \mathrm{C}_{4} \mathrm{H}_{10} \mathrm{O}\right)$, triclinic, $P \overline{1}$, $a=12.676(1), b=13.597(1), c=13.826(1) \mathrm{A}, \alpha=73.30(2), \beta=76.27(2)$, $\gamma=78.95(2)^{\circ}, V=2197.7(3) \AA^{3}, Z=2, T=123(2) \mathrm{K}, R_{1}=0.0640, \mathrm{w} R_{2}=$ 0.1902 .

$\S$ Additional details of the $\mathrm{C}-\mathrm{H} \cdots \pi$ and $\pi \cdots \pi$ interactions are available in the ESI. $\uparrow$

1 (a) R. Hoogenboom, G. Kickelbick and U. S. Schubert, Eur. J. Org. Chem., 2003, 4887; (b) W. Kaim, Coord. Chem. Rev., 2002, 230, 126; (c) L. K. Thompson, Coord. Chem. Rev., 2002, 233-234, 193.

2 V. J. Catalano, M. A. Malwitz, S. J. Horner and J. Vasquez, Inorg. Chem., 2003, 42, 2141.

3 L. Carlucci, G. Ciani, D. M. Proserpio and A. Sironi, Inorg. Chem., 1998, 37, 5941.

4 (a) P. H. Geyelin, S. A. Raw and R. J. K. Taylor, ARKIVOC, 2007, 37; (b) F. Thébault, A. J. Blake, C. Wilson, N. R. Champness and M. Schröder, New J. Chem., 2006, 30, 1498; (c) E. C. Constable, C. E. Housecroft, M. Neuburger, S. Reymann and S. Schaffner, Eur. J. Org. Chem., 2008, 1597.

5 (a) M.-T. Youinou, N. Rahmouni, J. Fischer and J. A. Osborn, Angew. Chem., Int. Ed. Engl., 1992, 31, 733; (b) B. L. Schottel, H. T. Chifotides, M. Shatruk, A. Chouai, L. M. Pérez, J. Basca and K. R. Dunbar, J. Am. Chem. Soc., 2006, 128, 5895; (c) N.-D. Sung, K.-S. Yun, T.-Y. Kim, K.-Y. Choi, M. Suh, J.-G. Kim, I.-H. Suh and J. Chin, Inorg. Chem. Commun., 2001, 4, 377; (d) N. Tsukada, T. Sato, H. Mori, S. Sugawara, C. Kabuto, S. Miyano and Y. Inoue, J. Organomet. Chem., 2001, 627, 121; (e) A. M. M. L. Lanfredi, A. Titipicchio, F. Ugozzoli, M. Ghedini and F. Neve, J. Chem. Soc., Dalton Trans., 1988, 651.

6 E. C. Constable, C. E. Housecroft, M. Neuburger, S. Reymann and S. Schaffner, Chem. Commun., 2004, 1056.

7 S. Ghumaan, B. Sarkar, S. Patra, K. Parimal, J. van Slageren, J. Fiedler, W. Kain and G. K. Lajiri, Dalton Trans., 2005, 706.

8 The guest water molecules show high thermal parameters, even after collecting the data at low temperature (123(2) K). So the electron density corresponding to the solvent molecules was removed from the reflection file using the SQUEEZE option in PLATON and refined. The resultant sqf file is appended to the CIF $\dagger$.

9 (a) E. Demers, T. Maris, J. Cabana, J.-H. Fournier and J. D. Wuest, Cryst. Growth Des., 2005, 5, 1237; (b) E. Demers, T. Maris and J. D. Wuest, Cryst. Growth Des., 2005, 5, 1227; (c) J. Fraxedas, Molecular Organic Materials: From Molecules to Crystalline Solids, Cambridge University Press, Cambridge, 2006.

10 (a) R. A. Carboni and R. V. Lindsey, J. Am. Chem. Soc., 1959, 81, 4342; (b) W. A. Butte and F. H. Case, J. Org. Chem., 1961, 26, $4690-4692$. 